\title{
Oral diseases and oral health related behaviors in adolescents living in Maasai population areas of Tanzania: a cross- sectional study
}

Lutango D. Simangwa ${ }^{1 *}$ (D, Anne N. Åstrøm², Anders Johansson ${ }^{3}$, Irene K. Minja ${ }^{4}$ and Ann-Katrin Johansson ${ }^{1}$

\begin{abstract}
Background: Oral diseases, such as dental caries, tooth wear, dental erosion and periodontal diseases are major health problems in many societies. The study aim was to explore the association between oral health related behaviors and the presence of oral diseases in adolescents living in Maasai population areas in the northern part of Tanzania.

Methods: A cross sectional study was conducted in 2016 using one stage cluster sample design. A total of 989 adolescents were invited and 906 (91.6\%; (Maasais $n=721$, non Maasais $n=185$ ) accepted the invitation and completed an interview and clinical oral examination in a school setting (mean age 13.4 years, SD 1.2, range 12-17 years). Chi-square test, bivariate analysis and logistic regression were performed to analyze data.

Results: Logistic regression revealed that: adolescents with low frequency of tooth cleaning $(O R=10.0, \mathrm{Cl} 4.3-20.0)$ was associated with poor oral hygiene and that more regular tooth cleaning $(\mathrm{OR}=0.1, \mathrm{Cl} 0.04-0.14)$ and the use of plastic type of tooth brush $(\mathrm{OR}=0.7, \mathrm{Cl} 0.53-0.99)$ were associated with less gingival bleeding. High consumption of biscuits ( $\mathrm{OR}=2.5, \mathrm{Cl} 1.7-3.8)$ was associated with presence of dental caries and the use of magadi $(\mathrm{OR}=24.2, \mathrm{Cl}$ 11.6-50.6) as a food additive was the covariate for more severe dental fluorosis (TF grade 5-9). Regular intake of carbonated soft drinks ( $O R=1.6, \mathrm{Cl} 1.1-2.5)$ and regular tooth cleaning $(\mathrm{OR}=1.7, \mathrm{Cl} 1.1-2.6)$ were independently associated with dental erosion. Using teeth as a tool for: biting nails $(\mathrm{OR}=1.9, \mathrm{Cl} 1.4-2.4)$, opening soda ( $\mathrm{OR}=1.8, \mathrm{Cl}$ 1.4-2.4) and holding needles $(\mathrm{OR}=1.6, \mathrm{Cl} 1.3-2.1)$ were covariates for tooth wear. Adolescents who reported to clench/grind their teeth $(\mathrm{OR}=2.3, \mathrm{Cl} 1.5-3.7)$ was the only covariate for TMD. In several of the investigated factors, there were significant differences between the Maasai and non Maasai ethnic groups.

Conclusion: Oral health related behaviors have a significant impact on oral diseases/conditions among adolescents attending primary schools in Maasai population areas with obvious differences in behavior between the Maasai and non Maasai ethnic groups. There is a need for addressing oral health and to encourage behaviors that promote good oral health and dental care service utilization in this society.
\end{abstract}

Keywords: Adolescents, Maasai populated areas, Oral diseases, Oral health related behaviors

\footnotetext{
*Correspondence: Lutango.Simangwa@uib.no

'Department of Clinical Dentistry - Cariology, Faculty of Medicine, University

of Bergen, Bergen, Norway

Full list of author information is available at the end of the article
}

(c) The Author(s). 2019 Open Access This article is distributed under the terms of the Creative Commons Attribution 4.0 International License (http://creativecommons.org/licenses/by/4.0/), which permits unrestricted use, distribution, and reproduction in any medium, provided you give appropriate credit to the original author(s) and the source, provide a link to the Creative Commons license, and indicate if changes were made. The Creative Commons Public Domain Dedication waiver (http://creativecommons.org/publicdomain/zero/1.0/) applies to the data made available in this article, unless otherwise stated. 


\section{Background}

Oral diseases are among the major public health problems in many societies $[1,2]$. Research evidence suggest that oral health related behaviors, for example dietary habits and oral hygiene practices, are strongly related to the occurrence of oral diseases [3, 4]. Thus, oral diseases can often be avoided by modification of certain behaviors, for instance, the consumption of sugary or acidic foods and drinks, the exposure to fluoride and the level of oral hygiene practices [3-5]. Regarding the extent and severity of oral diseases, studies among adolescents aged 10-14 years from Tanzania (2010), Kenya (2012) and Uganda (2003) have revealed low prevalence of dental caries and the mean DMFT ranging from 0.3 to 0.7 [6-8]. Dental fluorosis is quite common in some regions of East African countries with a prevalence of $100 \%$ [9]. The prevalence of more severe dental fluorosis (grade $\geq \mathrm{V}$ ) according to Thylstrup Fejerskov Index in adolescents 1015 year olds in Kenya (2009) and Tanzania (2000) was found to be $48 \%$ and $10-34 \%$, respectively $[10,11]$. Severe dental erosion in adolescents have been reported worldwide with prevalence varying from 3 to $20 \%$ [12, 13]. There is no information on dental erosion from sub-Saharan Africa in adolescents. Temporomandibular disorders (TMD) are a significant public health problems reported to affect $3-11 \%$ of the population [14]. In sub-Saharan Africa, studies on TMD are rare, studies from Tanzania and Nigeria reported that $67 \%$ of the Tanzanian adults and $26 \%$ of the Nigerian young adults had some signs and symptoms of TMD $[15,16]$.

In addition to individual oral health related behaviors, access to professional oral health care and lack of knowledge in combination with shortage of economic resources are influencing the possibility for the individuals to maintain an adequate oral health $[17,18]$. It has to be considered that treatment of oral diseases is expensive, and in many developing countries reflected by the fact that the costs of treating children's dental caries alone would exceed the total health care budget for those children [19]. The majority of the population in sub-Saharan Africa do not have access to appropriate oral health care services, especially those living in the rural areas [20, 21]. As a consequence, untreated oral diseases might lead to pain, problems with eating/chewing, smiling as well as speaking and limiting individual's daily activities and quality of life [2]. In addition, other difficulties are related to life experiences and psychosocial factors including age, gender, education, ethnicity, language, anxiety, feeling of vulnerability, treatment need and cost, disability, beliefs and attitude towards oral health [20, 22-24].

In Tanzania there are more than 125 different ethnic groups. The Maasais is one of them living around the Arusha region in the Northern part of Tanzania. Historically the Maasai are believed to have originated from
Sudan and to have migrated through the river Nile into Kenya and then further on in- to Tanzania. Their migration is due to their traditionally nomadic lifestyle whereby they move from one region to another searching for greener pastures for their livestock. Due to this kind of lifestyle they do not have permanent houses [25]. Historically, the Maasais original survival depends much on pastoralism, but today their way of living is increasingly moving towards agro-pastoralism [26]. This follows that their traditional diet, consisting of mainly meat and milk products, nowadays more often will include farm products, such as maize, rice and potatoes. Changes in dietary patterns, may expose the Maasai society to a different pattern of both oral and general diseases [2]. Previous report from Tanzania have shown that oral diseases associate with oral health related behaviors [27]. One previous study have shown that oral diseases among young adolescents in the Maasai population areas in Tanzania are common [28]. However, associations between oral diseases/ and oral health related behaviors have not recently been investigated in this particular socio-cultural context.

This study aims to explore associations between oral health related behaviors and the presence of oral diseases, adjusted for socio-demographic factors, focusing on adolescents living in Maasai population areas in the northern part of Tanzania.

\section{Methods \\ Sample size}

The sample size 845 was estimated based on the assumption that the prevalence of dental erosion, among the adolescents would be $50 \%$, a margin error of $5 \%$ and confidence intervals of $95 \%$.

\section{Sampling technique}

A cross-sectional study was carried out, from June to November 2016, among adolescents living in Maasai population areas of Monduli and Longido districts, Arusha region in the Northern part of Tanzania. A list of all primary schools comprising public (urban and rural) and private schools (total of 100 schools) from both districts was obtained from the district education department. From this list all urban and private primary schools were excluded, leaving 66 eligible rural public primary schools (38 schools from Monduli and 28 from Longido district) for the sample frame. Urban and private schools were excluded because our main aim was to capture a maximum number of adolescents from pastoral societies living in remote rural areas and the majority of them cannot afford to attend private schools as they are very expensive. Out of these 66 schools, 23 schools were randomly selected (13 from Monduli and 10 from Longido) using a one-stage cluster sample 
design with schools as the primary sampling unit and random number generator software. From each randomly selected school a class expected to contain adolescents aged 12-14 years was identified (grade 6). All pupils in the selected classes meeting the inclusion criteria for age were invited to participate in the study. Further details of the sampling procedure has been described elsewhere [28].

\section{Interview}

In this paper, some of the methods used have been described in our previous work [28]. Trained medical nurses, native of the study area, who spoke both Swahili and Maasai language fluently, performed a face- to- face interview with each participant at school outside or inside the classroom, depending on availability. The participants were interviewed using a questionnaire with closed- and open-ended questions. The questions were constructed in English, translated into Swahili and backtranslated to English independently by qualified translators from the University of Dar Es Salaam, Tanzania. A pilot study ( $n=50$, age $12-14)$, testing the interview schedule, took place before the actual fieldwork regarding wording, meaning, and content on each item, and appropriateness of format. Participants of this pre-testing were not included in the main study [28].

Socio-demographic factors were assessed in terms of district of residence, age, sex, ethnicity, wealth index and mother's education. Details of the assessment of sociodemographic factors have been described elsewhere [28]. Wealth index was assessed by asking the presence/absence of durable household assets indicative of family wealth (i.e. radio, television, refrigerator, mobile telephone, cupboard, bicycle and motorcycle) was recorded as (Yes) "available and in working condition" or (No) "not available and/or not in working condition." Oral health related behaviors were assessed in terms of dietary habits, oral hygiene practices, alcohol, tobacco use, dental service utilization, sources of fluoride ingestion and use of teeth in their daily activities. Dietary habits were assessed by asking "How often do you eat" a particular type of food e.g. sweets, biscuits, sugar, honey, maize stiff porridge, rice, cassava, sweet potatoes, Irish potatoes, meat, boiled blood, beans, fish, groundnuts and "How often do you drink" a particular type of drink e.g. carbonated soft drink, fruit drink, water plain, water with sugar, tea plain, tea with sugar, blood from animals, fresh milk from animals and soured milk? Oral hygiene practice was assessed by asking two questions: "How often do you clean your teeth" and "Do you use toothpaste during tooth cleaning"? For both the dietary habits and oral hygiene practices the response categories were $0=$ never, $1=$ once to several times per month, $2=$ once weekly, $3=$ two or more times per week and $4=$ daily.
During analysis, the categories were dichotomized into $0=$ low frequency/at most once per week (with options 0,1 and 2) and $1=$ high frequency/at least twice per week (with options 3 and 4). The type of cleaning instrument used was assessed by asking "What type of cleaning instrument do you most often use to clean your teeth"? The responses were plastic type, chewing stick, charcoal or don't have. In logistic regression the options of charcoal and don't have were omitted due to fewer cases. The tobacco and alcohol habits were assessed by asking "How often do you smoke/chew tobacco" and "How often do you drink alcohol"? The response categories were $0=$ never, $1=$ once to several times per month, $2=$ once weekly, $3=$ two or more times per week and $4=$ daily. During analysis, the categories were dichotomized into $0=$ never (with option 0 ) and $1=$ irregularly (with options 1, 2, 3 and 4). Dental services utilization was assessed by asking "Before today, have you ever visited a dentist/dental therapist for toothache" and "Before today, have you ever visited a dentist/dental therapist for checkup"? The responses were "yes" or "no". If "yes", then the type of treatment that they received was requested. Source of fluoride ingestion from drinking water was assessed by asking "Where does your family get the drinking water?" The options were $1=$ tap, $2=$ well, $3=$ borehole, $4=$ spring, $5=$ lake, $6=$ river, $7=$ rain water, $8=$ stream. During analysis, the categories were dichotomized into $0=$ tap water (with option 1 ) and $1=$ non tap water (with options 2, 3, 4, 5, 6 and 7). In addition, we asked if their family uses magadi/masala/ginger as food additives when cooking. The options were "yes" or "no" for each item. During analysis the items were dichotomized into $0=$ family do not use magadi and $1=$ family uses magadi. Use of teeth in daily activities was assessed by asking "Do you use your teeth in any habit like: nail biting, pen/pencil biting, opening soda, holding needles, chewing sticks/roots/sunflower seeds etc."? The responses were "yes" or "no". As described elsewhere [28], prevalence of temporomandibular disorder (TMD) was assessed by asking two validated epidemiological questions: "Do you have pain in your temple, face, jaw or jaw joint once a week or more?" and "Does it hurt once a week or more when you open your mouth or chew?" The response was either "yes" or "no" and by having a positive response to one or all of the two questions was considered affirmative to TMD diagnosis [29].

In the multiple variable logistic regression analyses, each outcome variable had two levels/categories. Oral hygiene status was dichotomized into $0=$ poor oral hygiene and $1=$ good oral hygiene; gingival bleeding was dichotomized into $0=$ without bleeding and $1=$ with bleeding; dental caries was dichotomized into DMFT $=0$ and DMFT $>0$ and dental fluorosis was dichotomized into $0=\mathrm{TF}$ score $0-4$ and $1=\mathrm{TF}$ score $5-9$. In addition, 
dental erosion was dichotomized into $0=$ grade 0 and $1=$ grade $1-4$; tooth wear was dichotomized into $0=$ grade 0 and $1=$ grade $1-4$; and TMD was dichotomized into $0=$ without $\mathrm{TMD}$ symptoms and $1=$ with $\mathrm{TMD}$ symptoms.

\section{Oral clinical examination}

The principal investigator (LS) performed all clinical examinations. The participant was examined in natural day light under field conditions, sitting on a chair, outside or inside the classroom. The dentition was cleaned and dried by sterile gauze and isolated by cotton rolls, if necessary. Disposable mouth mirrors and Sickle probe (No. 23 explorer or Shepherd's hook) were used. Full report over the clinical findings has been reported elsewhere [28].

The Simplified Oral Hygiene Index (OHI-S) was used to assess the oral hygiene status [30]. This method also has been described elsewhere [28]. The scores were (0) for no plaque/calculus present, (1) for plaque or supragingival calculus covering not more than one third of the tooth surface, (2) for plaque or supra-gingival calculus covering more than one third but less than two thirds of the tooth surface, and (3) for plaque or supragingival calculus covering more than two thirds of the tooth surface.

Gingival Bleeding Index (GBI) was used to assess the gingival health [31]. Dental caries was assessed according to criteria specified by WHO, 2013 [32] and dental fluorosis by Thylstrup- Fejerskov - index (TF-index) on all buccal surfaces, except wisdoms teeth [33]. Dental erosion was partially recorded according to Johansson et al. 1996 [34] for palatal and facial surfaces of maxillary anterior teeth, and by the scale of Hasselkvist et al. [35] for grading cuppings of first molars. Tooth wear was graded as a full mouth recording of occlusal/incisal surfaces of all teeth according to Carlsson et al. 1985 [36].

\section{Statistical analysis}

The Statistical Package for Social Sciences (SPSS) for PC version 25 (IBM corporation, Armonk, NY, USA) and STATA 15.0 (Stata corporation, Lakeway drive college station, Texas, USA) were used for data analysis. Descriptive statistics were carried out, followed by bivariate analysis using cross tabulations and Pearson's chi-square statistical test. Intra-examiner concordances were examined using percentage agreement and Cohen's Kappa. Multiple variable logistic regression analyses were performed to assess associations between oral health behaviors and oral diseases/conditions whilst adjusting for potential confounding factors in terms of socio-demographics (sex, age group, district, ethnicity, wealth index and maternal education) and using odds ratio (OR) and 95\% confidence intervals (CI). Oral health related behaviors, significantly associated with oral diseases/ conditions in unadjusted bivariate analyses were included in the multiple logistic regression analyses. The analyses were adjusted for the cluster of school, the primary sampling unit in this study. Level for statistical significance was set to $p<0.05$.

\section{Results}

\section{Sample characteristics}

A total of 906 adolescents attending primary school grade 6 participated in this study (response rate 91.6\%). Initially, a total of 989 adolescents were invited to participate, out of which $59(6.0 \%)$ were absent during interviewing and $24(2.6 \%)$ were excluded during analysis because of too high or low age. The age range finally accepted for participation in the study was $12-17$ years (mean age 13.4 years, SD 1.2) and 56.1\% of those were females. A total of 52.9 and $47.1 \%$ of the adolescents were from Monduli and Longido districts, respectively. Among the participants, $79.6 \%$ were from the Maasai ethnic group and $20.4 \%$ from the non Maasai ethnic group. For details of sociodemographic features and oral diseases/conditions frequency distribution in the total sample see Table 1.

\section{Reliability testing}

During training for scoring of dental erosion, the interexaminer (between LS and AKJ) Cohen's Kappa for all examined teeth during examination was 0.82 . Oral clinical examination was carried out by the principal investigator (LS). Duplicate clinical examinations were carried out with 93 randomly selected participants 3 weeks apart. Intra-examiner reliability as per Cohen's Kappa value was 0.98 for DMFT, 0.87 for TF index and 0.69 for dental erosion.

\section{Oral health related behaviors by ethnic group}

As shown in Tables 2 and 3, a majority of the oral health related behaviors investigated varied significantly $(p<$ 0.001) with ethnic group belongingness with the exception of eating sweets, drinking sour milk, meat consumption, use of teeth for nail biting, pencil biting, opening soda and holding needle, eating vegetables and fruits, and having a behavior of clenching and/or grinding teeth. Totals of $32.6 \%$ of the Maasai and $47.0 \%$ of the non Maasai adolescents reported high frequency of intake of biscuits. The ethnic distribution for use of plastic toothbrush and chewing sticks were respectively, $39.8 \%$ versus $74.6 \%(p<0.001)$ and $53.7 \%$ versus $21.1 \%$ $(p<0.001)$ for Masaai and non-Masaai, respectively.

\section{Oral diseases by oral health related behaviors}

Socio-demographic and oral health related behaviors significantly associated with oral health outcomes in unadjusted analyses, were included as covariates in the 
Table 1 Frequency distribution of sociodemographic features and oral diseases/conditions in a total sample, $N=906$

\begin{tabular}{|c|c|c|}
\hline Sociodemographic feature & Category & Frequency \% (n) \\
\hline \multirow[t]{2}{*}{ District of residence } & Monduli & $52.9(479)$ \\
\hline & Longido & $47.1(427)$ \\
\hline \multirow[t]{2}{*}{ Sex } & Male & 43.9 (398) \\
\hline & Female & $56.1(508)$ \\
\hline \multirow[t]{2}{*}{ Age } & $12-14$ years & $87.3(777)$ \\
\hline & $15-17$ years & $12.7(113)$ \\
\hline \multirow[t]{2}{*}{ Ethnicity } & Maasai & $79.6(721)$ \\
\hline & Non Maasai & $20.4(185)$ \\
\hline \multirow[t]{2}{*}{ Wealth Index } & Most poor & $48.8(438)$ \\
\hline & Least poor & $51.2(459)$ \\
\hline \multirow[t]{2}{*}{ Mother's education } & Low ( $\leq$ primary school) & $95.0(861)$ \\
\hline & High ( $\geq$ secondary school) & $5.0(45)$ \\
\hline \multirow[t]{2}{*}{ Oral hygiene status } & Poor (OHI-S $\geq 1)$ & $65.6(594)$ \\
\hline & Good $(\mathrm{OHI}-\mathrm{S}<1)$ & $34.4(312)$ \\
\hline \multirow[t]{2}{*}{ Gingival bleeding } & Negative & $59.1(535)$ \\
\hline & Positive & $40.9(371)$ \\
\hline \multirow[t]{2}{*}{ Dental caries } & $\mathrm{DMFT}=0$ & $91.2(826)$ \\
\hline & DMFT $>0$ & $8.8(80)$ \\
\hline \multirow[t]{2}{*}{ Dental fluorosis } & TF score 0 & $10.3(93)$ \\
\hline & TF score 1-9 & 89.7 (813) \\
\hline \multirow[t]{2}{*}{ Dental fluorosis } & TF score $0-4$ & $51.4(466)$ \\
\hline & TF score 5-9 & $48.6(440)$ \\
\hline \multirow[t]{2}{*}{ Dental erosion } & Grade $0-2$ & $98.1(889)$ \\
\hline & Grade 3-4 (extending into dentine) & $1.9(17)$ \\
\hline \multirow[t]{2}{*}{ Dental erosion } & Grade 0 & $70.0(634)$ \\
\hline & Grade 1-4 & $30.0(272)$ \\
\hline \multirow[t]{2}{*}{ Tooth wear } & Grade $0-1$ & $83.5(757)$ \\
\hline & Grade $2-4$ (extending into dentine) & $16.5(149)$ \\
\hline \multirow[t]{2}{*}{ TMD pain } & No & $88.2(799)$ \\
\hline & Yes & $11.8(107)$ \\
\hline
\end{tabular}

multiple variable logistic regression. Tables 4, 5, 6 and 7 depicts unadjusted frequency distributions and the ORs and 95\% CI for oral hygiene, gingival bleeding, caries experience, dental fluorosis, dental erosion, tooth wear and TMD by oral health related behaviors whilst adjusted for sociodemographic characteristics.

As shown in Table 4, frequency of tooth cleaning was statistically significantly associated with oral hygiene status, whereas frequency of tooth cleaning and type of toothbrush were significantly associated with gingival bleeding both in bivariate and multiple variable logistic regression analyses. As compared to adolescents reporting high frequency of tooth cleaning, those who reported low frequency were significantly more likely to present with poor oral hygiene status. The corresponding OR was 10.0 (95\% CI 4.3-20.0). Adjusted ORs for presenting with gingival bleeding were 0.1 (95\% CI 0.04-0.14) if reporting high versus low frequency of tooth cleaning and 0.7 (95\% CI 0.53-0.99) if reporting use of plastic toothbrush versus chewing stick.

Frequency of eating biscuits was the only behavior that was significantly associated with caries experience in both unadjusted and adjusted analyses. As compared to adolescents reporting low frequency of intake, their counterparts who reported high intake frequency were 2.5 times (OR 2.5, 95\% CI 1.7-3.8) more likely to present with DMFT $>0$ after having adjusted for socio-demographic characteristics. Those who reported use of magadi, compared to those who did not, were more likely to present with dental fluorosis (TF 5-9, OR 24.2 (95\% CI 11.6-50.6). For more details see Table 5 . 
Table 2 Frequency distribution of oral health related behaviors (dietary and oral hygiene) overall and by ethnic groups

\begin{tabular}{|c|c|c|c|c|}
\hline Variable & Overall $(N=906) \%(n)$ & Maasai $(n=721) \%(n)$ & non Maasai $(n=185) \%(n)$ & $p$-value ${ }^{*}$ \\
\hline \multicolumn{5}{|l|}{ Frequency of: Eating sweets } \\
\hline Low (s1per week) & $60.8(551)$ & $62.4(450)$ & $54.6(101)$ & \\
\hline High ( $\geq 2$ per week or daily) & $39.2(355)$ & $37.6(271)$ & $45.4(84)$ & 0.052 \\
\hline \multicolumn{5}{|l|}{ Eating biscuits } \\
\hline Low ( $\leq 1$ per week) & $64.5(584)$ & $67.4(486)$ & $53.0(98)$ & \\
\hline High ( $\geq 2$ per week or daily) & $35.5(322)$ & $32.6(235)$ & $47.0(87)$ & $<0.001$ \\
\hline \multicolumn{5}{|l|}{ Drinking carbonated soft drinks } \\
\hline Low ( $\leq 1$ per week) & $66.3(601)$ & $70.2(506)$ & $51.4(95)$ & \\
\hline High ( $\geq 2$ per week or daily) & $33.7(305)$ & $29.8(215)$ & $48.6(90)$ & $<0.001$ \\
\hline \multicolumn{5}{|l|}{ Drinking fruit drink } \\
\hline Low ( $\leq 1$ per week) & $68.7(622)$ & $71.8(518)$ & $56.2(104)$ & \\
\hline High ( $\geq 2$ per week or daily) & $31.3(284)$ & $28.2(203)$ & $43.8(81)$ & $<0.001$ \\
\hline \multicolumn{5}{|l|}{ Drinking tea with sugar } \\
\hline Low ( $\leq 1$ per week) & $21.7(197)$ & $24.7(178)$ & $10.3(19)$ & \\
\hline High ( $\geq 2$ per week or daily) & $78.3(709)$ & $75.3(543)$ & $89.7(166)$ & $<0.001$ \\
\hline \multicolumn{5}{|l|}{ Drinking tea without sugar } \\
\hline Low ( $\leq 1$ per week) & $88.7(804)$ & $87.5(631)$ & $93.5(173)$ & \\
\hline High ( $\geq 2$ per week or daily) & $11.3(102)$ & $12.5(90)$ & $6.5(12)$ & 0.021 \\
\hline \multicolumn{5}{|l|}{ Drinking milk from cows } \\
\hline Low ( $\leq 1$ per week) & $17.9(162)$ & $14.1(102)$ & $32.4(60)$ & \\
\hline High ( $\geq 2$ per week or daily) & $82.1(744)$ & 85.9 (619) & $67.6(125)$ & $<0.001$ \\
\hline \multicolumn{5}{|l|}{ Drinking soured milk } \\
\hline Low ( $\leq 1$ per week) & $41.7(378)$ & 41.5 (299) & $42.7(79)$ & \\
\hline High ( $\geq 2$ per week or daily) & $58.3(528)$ & $58.5(422)$ & $57.3(106)$ & 0.762 \\
\hline \multicolumn{5}{|l|}{ Eating meat } \\
\hline Low ( $\leq 1$ per week) & $55.4(502)$ & $56.7(409)$ & $50.3(93)$ & \\
\hline High ( $\geq 2$ per week or daily) & $44.6(404)$ & $43.3(312)$ & $49.7(92)$ & 0.115 \\
\hline \multicolumn{5}{|l|}{ Cleaning teeth } \\
\hline Low (s1per week) & $24.6(223)$ & $27.2(196)$ & $14.6(27)$ & \\
\hline High ( $\geq 2$ per week or daily) & $75.4(683)$ & $72.8(525)$ & $85.4(158)$ & $<0.001$ \\
\hline \multicolumn{5}{|l|}{ Using toothpaste } \\
\hline Low ( $\leq 1$ per week) & $62.4(565)$ & $69.6(502)$ & $34.1(63)$ & \\
\hline High ( $\geq 2$ per week or daily) & $37.6(341)$ & $30.4(219)$ & $65.9(122)$ & $<0.001$ \\
\hline \multicolumn{5}{|l|}{ Type of tooth brush } \\
\hline Plastic & $46.9(425)$ & $39.8(287)$ & $74.6(138)$ & \\
\hline Chewing stick & $47.0(426)$ & $53.7(387)$ & $21.1(39)$ & \\
\hline Charcoal & $0.7(6)$ & $0.8(6)$ & $0.0(0)$ & \\
\hline Don't have & $5.4(49)$ & $5.7(41)$ & $4.3(8)$ & $<0.001$ \\
\hline
\end{tabular}

*Pearson's Chi-square teik

In the adjusted regression analyses (Table 6), those who reported high frequency of intake of carbonated soft drinks (OR $=1.6,95 \%$ CI 1.1-2.5) and cleaning teeth $(\mathrm{OR}=1.7,95 \%$ CI 1.2-2.6), were more likely to present with dental erosion. Biting nails $(\mathrm{OR}=1.9,95 \%$ CI $1.4-$ 2.4), using teeth for opening soda and holding needles
$(\mathrm{OR}=1.8,95 \%$ CI $1.4-2.4$ and $\mathrm{OR}=1.6,95 \% \mathrm{CI} 1.3-2.1$, respectively), and using chewing stick type $(\mathrm{OR}=1.7$, 95\% CI 1.3-2.5) were significantly associated to increased severity of tooth wear.

Adolescents who reported clenching and/or grinding teeth $(\mathrm{OR}=2.3,95 \% \mathrm{CI} 1.5-3.7)$ were more likely to 
Table 3 Frequency distribution of oral health related behaviors (dental fluorosis, daily use of teeth as tool and TMD) overall and by ethnic groups

\begin{tabular}{|c|c|c|c|c|}
\hline Variable & Overall $(N=906) \%(n)$ & Maasai $(n=721) \%(n)$ & Non Maasai $(n=185) \%(n)$ & $p$-value \\
\hline \multicolumn{5}{|c|}{ Source of drinking water } \\
\hline Tap water & $56.7(514)$ & $49.8(359)$ & $83.8(155)$ & \\
\hline Non tap water & $43.3(392)$ & $50.2(362)$ & $16.2(30)$ & 0.001 \\
\hline \multicolumn{5}{|c|}{ Family uses magadi } \\
\hline No & $59.9(483)$ & $57.7(374)$ & $69.0(109)$ & \\
\hline Yes & $40.1(323)$ & $42.3(274)$ & $31.0(49)$ & 0.010 \\
\hline \multicolumn{5}{|c|}{ Do you use teeth for nail biting? } \\
\hline No & $54.9(497)$ & $55.9(403)$ & $50.8(94)$ & \\
\hline Yes & $45.1(409)$ & $44.1(318)$ & $49.2(91)$ & 0.215 \\
\hline \multicolumn{5}{|c|}{ Do you use teeth for pen/pencil biting? } \\
\hline No & $58.1(526)$ & $58.9(425)$ & $54.6(101)$ & \\
\hline Yes & $41.9(380)$ & $41.1(296)$ & $45.4(81)$ & 0.285 \\
\hline \multicolumn{5}{|c|}{ Do you use teeth for opening soda? } \\
\hline No & $48.2(437)$ & $48.1(347)$ & $48.6(90)$ & \\
\hline Yes & $51.8(469)$ & $51.9(374)$ & $51.4(95)$ & 0.899 \\
\hline \multicolumn{5}{|c|}{ Do you use teeth for holding needle? } \\
\hline No & $57.9(525)$ & $57.6(415)$ & $59.5(110)$ & \\
\hline Yes & $42.1(381)$ & $42.4(306)$ & $40.5(75)$ & 0.640 \\
\hline \multicolumn{5}{|c|}{ Do you use teeth for chewing sticks? } \\
\hline No & $57.1(517)$ & $55.2(398)$ & $64.3(119)$ & \\
\hline Yes & $42.9(389)$ & $44.8(323)$ & $35.7(66)$ & 0.025 \\
\hline \multicolumn{5}{|c|}{ Do you use teeth for chewing roots? } \\
\hline No & $61.0(553)$ & $56.7(409)$ & $77.8(144)$ & \\
\hline Yes & $39.0(353)$ & $43.3(312)$ & $22.2(41)$ & $<0.001$ \\
\hline \multicolumn{5}{|c|}{ Do you use teeth for chewing sunflower? } \\
\hline No & $57.3(519)$ & $58.9(425)$ & $50.8(94)$ & \\
\hline Yes & $42.7(387)$ & $41.1(296)$ & $49.2(91)$ & 0.046 \\
\hline \multicolumn{5}{|c|}{ Do you eat vegetables? } \\
\hline No & $11.5(104)$ & $11.8(85)$ & $10.3(19)$ & \\
\hline Yes & $88.5(802)$ & $88.2(636)$ & $89.7(166)$ & 0.563 \\
\hline \multicolumn{5}{|l|}{ Do you eat fruits } \\
\hline No & $4.6(42)$ & $5.0(36)$ & $3.2(6)$ & \\
\hline Yes & $95.4(864)$ & $95.0(685)$ & $96.8(179)$ & 0.313 \\
\hline \multicolumn{5}{|c|}{ Do you clench or grind your teeth? } \\
\hline No & $64.8(587)$ & $64.8(467)$ & $64.9(120)$ & \\
\hline Yes & $19.1(173)$ & $19.0(137)$ & $19.5(36)$ & \\
\hline I don't know & $16.1(146)$ & $16.2(117)$ & $15.7(29)$ & 0.978 \\
\hline
\end{tabular}

*Pearson's Chi-square test

present with TMD pain compared to those who did not (Table 7).

\section{Discussion}

This study aimed to explore the association between oral health related behavior and oral diseases in adolescents living in Maasai population areas of Tanzania. As earlier reported, poor oral hygiene, gingival bleeding and dental fluorosis were common findings among this group of adolescents while dental caries, dental erosion, tooth wear and TMD symptoms were less common. Ethnic disparities predominated with respect to gingival bleeding, 
Table 4 Oral hygiene status and gingival bleeding according to oral health related behaviors. Unadjusted a Chi square and adjusted multiple variable logistic regression analyses

\begin{tabular}{|c|c|c|c|}
\hline Dependent variable & Independent variables & Unadjusted analysis \% ( $n)$ & Adjusted OR $(95 \% \mathrm{Cl})^{\mathrm{a}}$ \\
\hline \multirow[t]{6}{*}{ Oral hygiene status (poor hygiene) } & Frequency of cleaning teeth & & \\
\hline & High ( $\geq 2$ per week or daily) & $56.4(385)$ & 1 \\
\hline & Low ( $\leq 1$ per week) & $93.7(209)^{*}$ & $10.0(4.3-20.0)$ \\
\hline & Type of cleaning instrument & & \\
\hline & Chewing stick & $67.6(288)$ & 1 \\
\hline & Plastic & $60.2(256)^{*}$ & $0.9(0.7-1.3)$ \\
\hline \multirow[t]{6}{*}{ Gingival bleeding (Yes) } & Frequency of cleaning teeth & & \\
\hline & Low ( $\leq 1$ per week) & $84.3(188)$ & 1 \\
\hline & High ( $\geq 2$ per week or daily) & $26.8(183)^{*}$ & $0.1(0.04-0.14)$ \\
\hline & Type of cleaning instrument & & \\
\hline & Chewing stick & $45.5(194)$ & 1 \\
\hline & Plastic & $31.8(135)^{*}$ & $0.7(0.53-0.99)$ \\
\hline
\end{tabular}

*Significant Pearson Chi-square test $(p<0.05)$

${ }^{a}$ Multiple variable logistic regression analyses were adjusted for sex, age and ethnicity

dental caries and dental erosion [28]. In this study, there was a significant difference in some oral health related behavior between the Maasai and non Maasai groups. Low frequency of oral hygiene practices was associated with poor oral hygiene. High frequency of cleaning teeth and the use of plastic type of tooth brush were associated with less gingival bleeding. High consumption of biscuits was associated with presence of dental caries and the use of magadi as a food additive was associated with severe dental fluorosis (TF grade 5-9). Regular intake of carbonated soft drinks and regular tooth cleaning were covariates for dental erosion. Using teeth as a tool as for: biting nails, opening soda and holding needles were independently associated with tooth wear.

Table 5 Dental caries experience and dental fluorosis according to oral health related behaviors. Unadjusted Chi square and adjusted multiple variable logistic regression analyses

\begin{tabular}{|c|c|c|c|}
\hline Dependent variable & Independent variables & Unadjusted analysis \% ( $n)$ & Adjusted OR $(95 \% \mathrm{Cl})^{\mathrm{a}}$ \\
\hline \multirow[t]{12}{*}{ Dental caries experience (DMFT>0) } & \multicolumn{3}{|l|}{ Frequency of eating biscuits } \\
\hline & Low (s1per week) & $5.8(34)$ & 1 \\
\hline & High ( $\geq 2$ per week or daily) & $14.3(46)^{*}$ & $2.5(1.7-3.8)$ \\
\hline & \multicolumn{3}{|c|}{ Frequency of drinking tea with sugar } \\
\hline & Low ( $\leq 1$ per week) & $9.6(19)$ & \\
\hline & High ( $\geq 2$ per week or daily) & $8.6(61)$ & \\
\hline & \multicolumn{3}{|c|}{ Frequency of drinking milk from cows } \\
\hline & Low ( $\leq 1$ per week) & $5.6(9)$ & \\
\hline & High ( $\geq 2$ per week or daily) & $9.5(71)$ & \\
\hline & \multicolumn{3}{|l|}{ Frequency of tooth cleaning } \\
\hline & Low ( $\leq 1$ per week) & $9.0(20)$ & \\
\hline & High ( $\geq 2$ per week or daily) & $8.8(60)$ & \\
\hline \multirow[t]{6}{*}{ Dental fluorosis (TF grade 5-9) } & \multicolumn{3}{|l|}{ Source of drinking water } \\
\hline & Tap water & $41.2(212)$ & 1 \\
\hline & Non tap water & $58.2(228)^{*}$ & $1.3(0.6-2.8)$ \\
\hline & \multicolumn{3}{|l|}{ Family uses magadi } \\
\hline & No & $24.4(118)$ & 1 \\
\hline & Yes & $90.4(292)^{*}$ & $24.2(11.6-50.6)$ \\
\hline
\end{tabular}


Table 6 Dental erosion and tooth wear according to oral health related behaviors. Unadjusted a Chi square and adjusted multiple variable logistic regression analyses

\begin{tabular}{|c|c|c|c|}
\hline Dependent variable & $\begin{array}{l}\text { Independent } \\
\text { variables }\end{array}$ & $\begin{array}{l}\text { Unadjusted } \\
\text { analysis \% (n) }\end{array}$ & $\begin{array}{l}\text { Adjusted } \\
\text { OR }(95 \% \mathrm{Cl})^{\mathrm{a}}\end{array}$ \\
\hline \multirow[t]{18}{*}{ Dental erosion (grade 1-4) } & \multicolumn{3}{|c|}{ Frequency of drinking carbonated soft drinks } \\
\hline & Low( $\leq$ once per week) & $23.1(139)$ & 1 \\
\hline & High ( $\geq$ twice per week) & $44.3(135)^{*}$ & $1.6(1.1-2.5)$ \\
\hline & \multicolumn{3}{|l|}{ Frequency of drinking fruit drink } \\
\hline & Low( $\leq$ once per week) & $24.0(149)$ & 1 \\
\hline & High ( $\geq$ twice per week) & $44.0(125)^{*}$ & $1.5(1.0-2.2)$ \\
\hline & \multicolumn{3}{|c|}{ Frequency of drinking milk from cows } \\
\hline & Low ( $\leq 1$ per week) & $35.8(58)$ & 1 \\
\hline & High ( $\geq 2$ per week or daily) & $29.0(216)^{*}$ & $0.7(0.5-1.0)$ \\
\hline & \multicolumn{3}{|l|}{ Eating meat } \\
\hline & Low ( $\leq 1$ per week) & $25.3(127)$ & 1 \\
\hline & High ( $\geq 2$ per week or daily) & $36.4(147)^{*}$ & $1.3(0.9-2.0)$ \\
\hline & \multicolumn{3}{|l|}{ Frequency of cleaning teeth } \\
\hline & Low ( $\leq 1$ per week) & $19.7(44)$ & 1 \\
\hline & High ( $\geq 2$ per week or daily) & $33.7(230)^{*}$ & $1.7(1.1-2.6)$ \\
\hline & \multicolumn{3}{|l|}{ Frequency of using tooth paste } \\
\hline & Low( $\leq$ once per week) & $25.5(144)$ & 1 \\
\hline & High ( $\geq 2 x$ per week) & $38.1(130)^{*}$ & $1.1(0.7-1.8)$ \\
\hline \multirow[t]{24}{*}{ Tooth wear (Grade 1-4) } & \multicolumn{3}{|c|}{ Frequency of drinking carbonated soft drinks } \\
\hline & Low( $\leq$ once per week) & $46.3(278)$ & \\
\hline & High ( $\geq$ twice per week) & $45.6(139)$ & \\
\hline & \multicolumn{3}{|l|}{ Frequency of drinking fruit drink } \\
\hline & Low( $\leq$ once per week) & $46.9(292)$ & \\
\hline & High ( $\geq$ twice per week) & $44.0(125)$ & \\
\hline & \multicolumn{3}{|c|}{ Frequency of drinking milk from cows } \\
\hline & Low ( $\leq 1$ per week) & $50.0(81)$ & \\
\hline & High ( $\geq 2$ per week or daily) & $45.2(336)$ & \\
\hline & \multicolumn{3}{|l|}{ Frequency of cleaning teeth } \\
\hline & Low ( $\leq 1$ per week) & $51.1(114)$ & 1 \\
\hline & High ( $\geq 2$ per week or daily) & $44.4(303)^{*}$ & $0.8(0.6-1.1)$ \\
\hline & \multicolumn{3}{|l|}{ Type of cleaning instrument } \\
\hline & Chewing stick & $50.9(217)$ & 1 \\
\hline & Plastic & $40.7(173)^{*}$ & $0.6(0.4-0.8)$ \\
\hline & \multicolumn{3}{|l|}{ Frequency of using tooth paste } \\
\hline & Low( $\leq$ once per week) & $46.5(263)$ & \\
\hline & High ( $\geq 2 x$ per week) & $45.2(154)$ & \\
\hline & \multicolumn{3}{|l|}{ Uses teeth for nail biting } \\
\hline & No & $35.8(178)$ & 1 \\
\hline & Yes & $58.4(239)^{*}$ & $1.9(1.4-2.4)$ \\
\hline & \multicolumn{3}{|l|}{ Uses teeth for pen/pencil biting } \\
\hline & No & $41.4(218)$ & 1 \\
\hline & Yes & $52.4(199)^{*}$ & $0.9(0.6-1.3)$ \\
\hline
\end{tabular}

Uses teeth for opening soda 
Table 6 Dental erosion and tooth wear according to oral health related behaviors. Unadjusted a Chi square and adjusted multiple variable logistic regression analyses (Continued)

\begin{tabular}{llll}
\hline Dependent variable & $\begin{array}{l}\text { Independent } \\
\text { variables }\end{array}$ & $\begin{array}{l}\text { Unadjusted } \\
\text { analysis \% (n) }\end{array}$ & $\begin{array}{l}\text { Adjusted } \\
\text { OR (95\% Cl) }\end{array}$ \\
\hline No & $35.9(157)^{*}$ & 1 \\
Yes & $55.4(260)$ & $1.8(1.4-2.4)$ \\
Uses teeth for holding needles & $38.1(200)$ & 1 \\
No & $57.0(217)^{*}$ & $1.6(1.3-2.1)$ \\
Yes & & 1 \\
No teeth for chewing sunflower seeds & $50.6(221)^{*}$ & $1.0(0.8-1.3)$ \\
\hline
\end{tabular}

*Significant Pearson Chi-square test $(p<0.05)$

${ }^{a}$ Multiple variable logistic regression analyses were adjusted for ethnicity, maternal education and wealth index

Adolescents who reported to clench/grind their teeth was the only covariate for TMD.

Consistent with previous studies, low frequency of oral hygiene practices associated with poor oral hygiene and a high frequency of oral hygiene practices associated with less gingival bleeding [37, 38]. In addition a high frequency of intake of biscuits and carbonated soft drinks was associated with dental caries (DMFT $>0)$ and dental erosion, respectively $[35,39]$. Not surprisingly, those who reported to clean their teeth less often, had poorer oral hygiene status and more gingival bleeding compared to those who cleaned more often [40]. But, although $>75 \%$ of the adolescents reported a high frequency of tooth cleaning, the majority of them (66\%) had poor oral hygiene status. This imply that cleaning teeth twice to daily a week is not enough and/or that an ineffective cleaning technique was utilized or maybe there was over reporting of the frequency of oral hygiene habits.

In this study, the use of a wooden chewing stick (47\%) was less common than previous reports from rural areas of Kenya (59\%, 5-17 year olds) and Burkina Faso (64\%, 12 year olds), but more common than reports from the rural areas of Tanzania (4-36\%,5-22 year olds) [41-44]. On the other side, the use of a plastic tooth brush in this study (47\%) was more common than reports from Kenya (41\%) and Burkina Faso (36\%) [43, 44], but less common than earlier reports from Tanzania (64-96\%) [41, 42]. In this study, the use of a plastic tooth brush was correlated with less gingival bleeding. This finding is contrary to an earlier report from India where it was shown that there were no significant difference between the use of a chewing stick or a plastic toothbrush on gingival health [45]. Regarding ethnicity there was a significant difference between the ethnic groups in this study in terms of oral hygiene behavior. Compared to non Maasai group, the Maasai group reported to clean their teeth more irregularly and reported to use chewing sticks for cleaning teeth more regularly. The more common use of chewing sticks than plastic toothbrushes among the Masaai in this study might be a result of availability and economic considerations. In this regard, our previous report

Table 7 TMD pain according to oral health related behaviors. Unadjusted a Chi square and adjusted multiple variable logistic regression analyses

\begin{tabular}{|c|c|c|c|}
\hline Dependent variable & Independent variables & Unadjusted analysis \% (n) & Adjusted OR $(95 \% \mathrm{Cl})^{\mathrm{a}}$ \\
\hline \multirow[t]{9}{*}{$\overline{\mathrm{TMD}}(2 \mathrm{Q} / \mathrm{TMD}>0)^{\mathrm{b}}$} & Eating vegetables & & \\
\hline & No & $13.5(14)$ & \\
\hline & Yes & $11.6(93)$ & \\
\hline & Eating fruits & & \\
\hline & No & $9.5(4)$ & \\
\hline & Yes & $11.9(103)$ & \\
\hline & Do you clench or grind & & \\
\hline & No & $9.0(53)$ & 1 \\
\hline & Yes & $23.1(40)^{*}$ & $2.3(1.5-3.7)$ \\
\hline
\end{tabular}

*Significant Pearson Chi-square test $(p<0.05)$

${ }^{a}$ Multiple variable logistic regression analyses were adjusted for district of residence, ethnicity and mother's education

${ }^{b}$ Two epidemiological questions regarding TMD 
showed that the Maasai adolescents in this study were from more poor families compared to the non Maasais in terms of wealth index [28].

The low prevalence of dental caries found in this study (8.8\%) [28] imply a low exposure to cariogenic diet, which is supported by the findings in this study where the majority (60.8-64.5\%) of adolescents reported low intake of sweets and biscuits. The traditional diet for the Maasais is consisting of dairy products such as milk but also meat and blood from cattles, products with low cariogenic potential [46]. In this study, $82.1 \%$ of the adolescents reported high frequency of drinking fresh milk and this might have contributed to the low prevalence of dental caries among the adolescents [47]. In addition, a high fluoride content in their drinking water and using Magadi as food additive [48] may also have reduced their risk for dental caries [49]. Considering ethnicity, more adolescents from Maasai group (85.9\%) reported regular intake of fresh milk from cows and regular intake of magadi as food additives compared to non Maasais. Probably due to this, it is therefore not surprising to find that more Maasais were less affected by dental caries compared to non Maasais [28].

In this study a correlation between severe dental fluorosis and the use of Magadi as food additive was found, similar to other studies $[11,50]$. It is known that Magadi from Tanzania contain a high concentration of fluoride (160 to $1750 \mathrm{mg} / \mathrm{l}$ ) [51]. The Maasai group reported the use of Magadi more often than the non Maasais which may be one explanation for their higher prevalence and severity of dental fluorosis [28].

Probably the rural environment and poor economic situation in which study participants live might limit their access to erosive conducive challenges. But even so, about one third of all study participants reported to drink carbonated soft drinks and/or fruit juices regularly. Our previous study [28] revealed low prevalence (1.9\%) of dental erosion extending into dentine and there was a significant association between high frequency intake of carbonated soft drinks and dental erosion in this study, similar to others $[35,52]$. This study revealed also, in agreement with previous reports, an association between dental erosion and oral hygiene [53, 54]. In this regard, the Maasai adolescents reported significantly lesser teeth cleaning and use of toothpaste than non Maasais. Subsequently, the difference in dietary habits between the two ethnic groups in addition to more irregular oral hygiene practices may also explain why Maasais were less affected by dental erosion compared to non Maasais [28].

The severity and pattern of tooth wear could be influenced not only by acidic challenges such as soft drinks but also factors like abrasiveness of the diet, parafunctional habits and/or the use of teeth as tools $[55,56]$. Foods consumed in this society might often be hard and abrasive in nature, especially meat, since it is often mixed with ashes in the process of cooking and eaten when half cooked making it more abrasive to chew. The relative frequent intake of acidic drinks among the participants may also contribute to a worsening of the abrasive effect, resulting in more severe tooth wear [35]. About $45 \%$ of the study participants reported to use teeth for biting nails and 52\% reported to use teeth for opening soda bottles. The excessive biting force required for exercising these habits and the abrasiveness of the material involved in the practice could also have contributed to relatively high prevalence of tooth wear. However, the tooth wear process has a multifactorial etiology and other not investigated factors may have played a role as well [55].

This study found that self-reported bruxism was associated with TMD similar with previous reports $[57,58]$. Although previous reports have revealed that self-reported bruxism is associated with TMD, reports based on polysomnography (PSG) studies on sleep bruxism have not $[59,60]$. In this study, other parafunctional habits apart from bruxism, were not associated with development of TMD similar to previous reports [61].

A clear majority (about 95\%) of the adolescents in this study had never visited a dentist/dental therapist for toothache or checkup. The low dental service utilization indicates a need of actions that could facilitate access to these services. Oral health education is an essential and basic part of dental health care services as it provides information empowering people to raise awareness leading to the adoption of healthier lifestyles, positive attitudes and good oral health behaviors. It has been reported that oral health education is a powerful and successful tool in promoting oral health in adolescents [62] and that school provides a good setting for health-education programs [63]. In sub Saharan Africa, the health technology assessment (HTA) reports is scarce due to lack of capacity to undertake HTA and lack of high-quality data and lack of research evidence [64]. However, HTA reports from WHO suggests that structured research methodology and transparent and health procedures, including preventive intervention, helps to obtain information for evaluation of safety, cost-effectiveness, quality, and efficiency dimensions of such techniques when used in the health systems [65].

The strengths with the present study are the random sampling of the primary sampling units (schools), which may permit the generalization of the results to the communities living in Maasai populated areas. Using the research assistants fluent in both Swahili and Maasai language to interview the adolescents ensured that the interviewee had understood the question. In addition, one examiner performed the clinical examinations of all children thus reducing any inter-examiner variability. On the other side, using one examiner only may lead to 
introduction of observer effect bias where the observer may influence the participants of the study. Also it can lead to confirmation bias whereby the experinmenter interprets the results incorrectly because of the tendency to look for information that conforms to their hypothesis, and overlook information that argues against it [66]. However, since most of the background factors, such as dietary habits were based on self-report, it is always a possibility that the child might have misunderstood the question, forgotten or that the response might be influenced by social desirability. The cross-sectional method was utilized in data collection, making difficulties in establishing a causal relationship.

\section{Conclusion}

Oral health related behaviors have a significant impact on oral diseases/conditions among adolescents attending primary schools in Maasai population areas with obvious differences in behavior between the Maasai and non Maasai ethnic groups. There is a need for addressing oral health and to encourage behaviors that promote good oral health and dental care service utilization in this society.

\section{Abbreviations \\ Cl: Confidence Interval; DMFT: Decayed Missing Filled Tooth; GBI: Gingival Bleeding Index; HTA: Health Technology Assessment; OHI-S: Simplified Oral Hygiene Index; OR: Odds Ratio; SD: Standard Deviation; SPSS: Statistical Package for Social Sciences; TF-index: Thylstrup-Fejerskov-index; TMD: Temporomandibular Disorder; WHO: World Health Organisation}

\section{Acknowledgements}

We would like to thank the district education officers from Monduli and Longido districts for field work support and medical nurses/research assistants Mrs. Rose Lukumay, Ms. Ciriel Palanjo, Mrs. Joyce Mwanga and Mrs. Wema Laizer for their valuable contribution in this study. We also give our sincere thanks to parents, teachers and of course most of all, to all adolescents who participated in this study making this research possible.

\section{Authors' contributions}

LS: principal investigator, designed the study, collected the data, performed the statistical analyses, and wrote the manuscript. ANA: co-supervisor, designed the study, guided the statistical analyses and writing the manuscript. AJ: participated in the design of the study, guided the statistical analyses and writing the manuscript. IK: co-supervisor, participated in the design of the study and provided valuable guidance in the data collection and writing the manuscript. AKJ: main supervisor, designed the study, guided the statistical analyses and writing the manuscript. All authors read and approved the final manuscript.

\section{Authors' information}

LS: PhD candidate, University of Bergen, Bergen, Norway.

ANA: Professor, Department of Clinical Dentistry, University of Bergen, Bergen, Norway.

AJ: Professor, Department of Clinical Dentistry, University of Bergen, Bergen, Norway.

IK: Senior Lecturer, Department of Restorative Dentistry, Muhimbili University of Health and Allied Sciences, Dar Es salaam, Tanzania.

AKJ: Professor, Department of Clinical Dentistry, University of Bergen, Bergen, Norway.

\section{Funding}

The research was fully funded by Department of Clinical Dentistry, University of Bergen, Norway. The funding body didn't play any role in the design of the study and collection, analysis, and interpretation of data and in writing the manuscript.

\section{Availability of data and materials}

The datasets used and/or analyzed during the current study are available from the corresponding author on request.

\section{Ethics approval and consent to participate}

Prior to study implementation, ethical clearance from, the ethical research committee in Norway (REK VEST, reference number 2015/2477) and the Medical Research Coordinating Committee of Ministry of Health and Social Welfare in Tanzania (reference number NIMR/HQ/R.8a/VOL.IX/2214) were obtained. Permission to work with primary school adolescents was obtained from Ministry of Education and Vocational Training through Monduli and Longido district councils, their respective educational authorities, school teachers and parents. Informed written signed consent was obtained from the parents. Besides this the participating adolescents gave an assent. Confidentiality was ensured and participants were allowed to walk out of the study for whatever reason.

\section{Consent for publication}

Not applicable.

\section{Competing interests}

The authors declare that they have no competing interests.

\section{Author details}

${ }^{1}$ Department of Clinical Dentistry - Cariology, Faculty of Medicine, University of Bergen, Bergen, Norway. ${ }^{2}$ Department of Clinical Dentistry - Community Dentistry, Faculty of Medicine, University of Bergen, Bergen, Norway. ${ }^{3}$ Department of Clinical Dentistry - Prosthodontics, Faculty of Medicine, University of Bergen, Bergen, Norway. ${ }^{4}$ Department of Restorative Dentistry, School of Dentistry, Muhimbili University of Health and Allied Sciences, Dar Es Salaam, Tanzania.

Received: 18 January 2019 Accepted: 31 July 2019

Published online: 07 August 2019

\section{References}

1. Ab Halim N, Esa R, Chew HP. General and erosive tooth wear of 16-year-old adolescents in Kuantan, Malaysia: prevalence and association with dental caries. BMC Oral Health. 2018;18:11.

2. Petersen PE, Bourgeois D, Ogawa H, Estupinan-Day S, Ndiaye C. The global burden of oral diseases and risks to oral health. Bull World Health Organ. 2005;83:661-9.

3. Moynihan PJ. The role of diet and nutrition in the etiology and prevention of oral diseases. Bull World Health Organ. 2005:83:694-9.

4. Loe $\mathrm{H}$. Oral hygiene in the prevention of caries and periodontal disease. Int Dent J. 2000:50:129-39.

5. Lee $Y$. Diagnosis and prevention strategies for dental caries. J Lifestyle Med. 2013;3:107-9.

6. Mashoto KO, Astrom AN, Skeie MS, Masalu JR. Socio-demographic disparity in oral health among the poor: a cross sectional study of early adolescents in Kilwa district, Tanzania. BMC Oral Health. 2010;10:7.

7. Gathecha G, Makokha A, Peter Wanzala P, Omolo J, Smith P. Dental caries and oral health practices among 12 year old children in Nairobi west and Mathira west districts, Kenya. Pan Afr Med J. 2012;12:42.

8. Wandera M, Twa-Twa J. Baseline survey of oral health of primary and secondary school pupils in Uganda. Afr Health Sci. 2003;3(1):19-22.

9. Vuhahula EAM, Masalu JRP, Mabelya L, Wandwi WBC. Dental fluorosis in Tanzania great Rift Valley in relation to fluoride levels in water and in 'Magadi' (Trona). Desalination. 2009;248:610-5.

10. Makhanu M, Opinya G, Mutave RJ. Dental fluorosis, caries experience and snack intake of 13-15 year olds in Kenya. East Afr Med J. 2009:85:120-4.

11. Awadia AK, Bjorvatn K, Birkeland JM, Haugejorden O. Weaning food and magadi associated with dental fluorosis in northern Tanzania. Acta Odontol Scand. 2000:58:1-7.

12. Bardolia P, Burnside G, Ashcroft A, Milosevic A, Goodfellow SA, Rolfe EA, Pine CM. Prevalence and risk indicators of erosion in thirteen- to fourteenyear-olds on the Isle of Man. Caries Res. 2010;44:165-8. 
13. Al-Ashtal A, Johansson A, Omar R, Johansson AK. Dental erosion in groups of Yemeni children and adolescents and the modification of an erosion partial recording system. Int J Paediatr Dent. 2017;27:283-92.

14. Manfredini D, Guarda-Nardini L, Winocur E, Piccotti F, Ahlberg J, Lobbezoo F. Research diagnostic criteria for temporomandibular disorders: a systematic review of axis I epidemiologic findings. Oral Surg Oral Med Oral pathol Oral Radiol Endod. 2011;112:453-62.

15. Otuyemi OD, Owotade FJ, Ugboko VI, Ndukwe KC, Olusile OA. Prevalence of signs and symptoms of temporomandibular disorders in young Nigerian adults. J Orthod. 2000;27:61-5.

16. Fabian FM, Mumghamba EG. Risk factors for signs and symptoms of TMD in a rural adult southeast Tanzanian population. Cranio. 2008;26:44-9.

17. Varenne B, Petersen PE, Ouattara S. Oral health status of children and adults in urban and rural areas of Burkina Faso, Africa. Int Dent J. 2004;54:83-9.

18. World Health Organization (WHO). Promoting oral health in Africa: Prevention and control of oral diseases and noma as part of noncommunicable disease interventions. 2016. https://apps.who.int/iris/ bitstream/handle/10665/205886/9789290232971.pdf. Accessed 1 June 2017.

19. Yee $R$, Sheiham $A$. The burden of restorative dental treatment for children in third world countries. Int Dent J. 2002;52:1-9.

20. Ajayi DM, Arigbede AO. Barriers to oral health care utilization in Ibadan. South West Nigeria Afr Health Sci. 2012;12:507-13.

21. Varenne B, Petersen PE, Fournet F, Msellati P, Gary J, Ouattara S, et al. Illnessrelated behaviour and utilization of oral health services among adult citydwellers in Burkina Faso: evidence from a household survey. BMC Health Serv Res. 2006;6:164

22. Auad SM, Waterhouse PJ, Nunn JH, Moynihan PJ. Dental caries and its association with sociodemographics, erosion, and diet in schoolchildren from Southeast Brazil. Pediatr Dent. 2009;31:229-35.

23. Freeman R. Barriers to accessing dental care: patient factors. Br Dent J. 1999;187:141-4

24. Guay AH. Access to dental care: solving the problem for underserved populations. J Am Dent Assoc. 2004;135:1599-605.

25. African Roots Foundation. http://africanrootsfoundation.org/2008/the-lifehistory-of-maasai/. Accessed 09 Mar 2018.

26. Homewood K, Kristjanson P, Trench P. Staying Maasai: livelihoods, conservation and development in east African rangelands. New York: Springer; 2009.

27. Mbawalla HS, Masalu JR, Åstrøm AN. Socio-demographic and behavioural correlates of oral hygiene status and oral health related quality of life, the Limpopo - Arusha school health project (LASH): a cross-sectional study. BMC Pediatr. 2010;10:87.

28. Simangwa LD, Astrom AN, Johansson A, Minja IK, Johansson AK. Oral diseases and socio-demographic factors in adolescents living in Maasai population areas of Tanzania: a cross-sectional study. BMC Oral Health. 2018;18:200.

29. Nilsson IM, List T, Drangsholt M. The reliability and validity of selfreported temporomandibular disorder pain in adolescents. J Orofac Pain. 2006:20:138-44.

30. Greene JC, Vermillion JR. The simplified oral hygiene index. J Am Dent Assoc. 1964;68:7-13.

31. Ainamo J, Bay I. Problems and proposals for recording gingivitis and plaque. Int Dent J. 1975;25:229-35.

32. World Health Organization (WHO). Oral Health Surveys: Basic methods. 5th ed. Geneva: WHO; 2013. http://www.who.int/oral_health/publications/ 9789241548649/en/. Accessed 26 Aug 2017

33. Thylstrup A, Fejerskov O. Clinical appearance of dental fluorosis in permanent teeth in relation to histologic changes. Community Dent Oral Epidemiol. 1978;6:315-28.

34. Johansson AK, Johansson A, Birkhed D, Omar R, Baghdadi S, Carlsson GE. Dental erosion, soft-drink intake, and oral health in young Saudi men, and the development of a system for assessing erosive anterior tooth wear. Acta Odontol Scand. 1996:54:369-78.

35. Hasselkvist A, Johansson A, Johansson AK. Dental erosion and soft drink consumption in Swedish children and adolescents and the development of a simplified erosion partial recording system. Swed Dental J. 2010;34:187-95.

36. Carlsson GE, Johansson A, Lundqvist S. Occlusal wear: a follow-up study of 18 subjects with extensively worn dentitions. Acta Odontol Scand. 1985:43:83-90.

37. Hideki F, Cyril NO, Eunice K, Wagaiyu EG, Yoshihiko H. Oral health status among 12-year-old children in a rural Kenyan community. J Dent Oral Health. 2014;1:1-5.
38. Minor Babu MS, Nirmala SVSG, Sivakumar N. Oral hygiene status of 7-12 year old school children in rural and urban population of Nellore district. J Indian Assoc Public Health Dent. 2011;18(Suppl 3):1075-80.

39. Ferizi L, Dragidella F, Staka G, Bimbashi V, Mrasori S. Oral Health Status Related to Social Behaviors among 6-11 Year Old Schoolchildren in Kosovo. Acta Stomatol Croat. 2017;51:122-32.

40. Azodo CC, Agbor AM. Gingival health and oral hygiene practices of schoolchildren in the north west region of Cameroon. BMC Res Notes. 2015;8:385.

41. Carneiro L, Kabulwa M, Makyao M, Mrosso G, Choum R. Oral health knowledge and practices of secondary school students, Tanga, Tanzania. Int J Dent. 2011. https://doi.org/10.1155/2011/806258.

42. Nyandindi U, Palin-Palokas T, Milén A, Robison V, Kombe N. Oral health knowledge, attitudes, behaviour and skills of children entering school in urban and rural areas in Tanzania. Public Health. 1994;108:35-41.

43. Okemwa KA, Gatongi PM, Rotich JK. The oral health knowledge and oral hygiene practices among primary school children age 5-17 years in a rural area of Uasin Gishu district, Kenya. East Afr J Public Health. 2010;7:187-90.

44. Varenne B, Petersen PE, Ouattara S. Oral health behaviour of children and adults in urban and rural areas of Burkina Faso, Africa. Int Dent J. 2006;56:61-70.

45. Bhambal AB, Kothari SK, Saxena SS, Jain MJ. Comparative effect of neem stick and toothbrush on plaque removal and gingival health - a clinical trial. J Adv Oral Research. 2011;2:51-6.

46. Aatish Bhatia Science. Milk, meat and blood: how diet drives natural selection in the Maasai. Available at: https://www.wired.com/2012/09/milk-meat-andblood-how-diet-drives-natural-selection-in-the-maasai/. Accessed 31 Oct 2017.

47. Levy SM, Warren JJ, Broffitt B, Hillis SL, Kanellis MJ. Fluoride, beverages and dental caries in the primary dentition. Caries Res. 2003;37:157-65.

48. Awadia AK, Haugejorden O, Bjorvatn K, Birkeland JM. Vegetarianism and dental fluorosis among children in a high fluoride area of northern Tanzania. Int J Paediatr Dent. 1999:9:3-11.

49. Singh KA, Spencer AJ. Relative effects of pre- and post-eruption water fluoride on caries experience by surface type of permanent first molars. Community Dent Oral Epidemiol. 2004;32:435-46.

50. Awadia AK, Birkeland JM, Haugejorden O, Bjorvatn K. An attempt to explain why Tanzanian children drinking water containing 0.2 or 3.6 mg fluoride per liter exhibit a similar level of dental fluorosis. Clin Oral Investig. 2000:4:238-44.

51. Mabelya L, van Palenstein Helderman WH, van't Hof MA, Konig KG. Dental fluorosis and the use of a high fluoride-containing trona tenderizer (magadi). Community Dent Oral Epidemiol. 1997;25:170-6.

52. Jensdottir T, Holbrook P, Nauntofte B, Buchwald C, Bardow A. Immediate erosive potential of cola drinks and orange juices. J Dent Res. 2006;85:226-30.

53. Hemingway CA, Parker DM, Addy M, Barbour ME. Erosion of enamel by non-carbonated soft drinks with and without toothbrushing abrasion. $\mathrm{Br}$ Dent J. 2006;201:447-50.

54. Mantonanaki M, Koletsi-Kounari H, Mamai-Homata E, Papaioannou W. Dental erosion prevalence and associated risk indicators among preschool children in Athens, Greece. Clin Oral Investig. 2013;17:585-93.

55. Johansson A, Fareed K, Omar R. Analysis of possible factors influencing the occurrence of occlusal tooth wear in a young Saudi population. Acta Odontol Scand. 1991;49:139-45.

56. Kaidonis JA. Tooth wear: the view of the anthropologist. Clin Oral Investig. 2008;12:21-6.

57. Carlsson GE, Egermark I, Magnusson T. Predictors of signs and symptoms of temporomandibular disorders: a 20-year follow-up study from childhood to adulthood. Acta Odontol Scand. 2002;60:180-5.

58. Al-Khotani A, Naimi-Akbar A, Albadawi E, Ernberg M, Hedenberg-Magnusson B, Christidis N. Prevalence of diagnosed temporomandibular disorders among Saudi Arabian children and adolescents. J Headache Pain. 2016;17:41.

59. Rossetti LM, Rossetti PH, Conti PC, de Araujo Cdos R. Association between sleep bruxism and temporomandibular disorders: a polysomnographic pilot study. Cranio. 2008;26:16-24.

60. Raphael KG, Sirois DA, Janal MN, Wigren PE, Dubrovsky B, Nemelivsky LV, Klausner JJ, Krieger AC, Lavigne GJ. Sleep bruxism and myofascial temporomandibular disorders: a laboratory-based polysomnographic investigation. J Am Dent Assoc. 2012;143:1223-31.

61. Castelo PM, Gaviao MB, Pereira LJ, Bonjardim LR. Relationship between oral parafunctional/nutritive sucking habits and temporomandibular joint dysfunction in primary dentition. Int J Paediatr Dent. 2005;15:29-36.

62. Biesbrock AR, Walters PA, Bartizek RD. Initial impact of a national dental education program on the oral health and dental knowledge of children. J Contemp Dent Pract. 2003;2:1-10. 
63. WHO. Promoting health through schools. Report of a WHO Expert Committee on Comprehensive School Health Education and Promotion. World Health Organ Tech Rep Ser. 1997;870:1-93.

64. Kriza C, Hanass-Hancock J, Odame EA, Deghaye N, Aman R, Wahlster P, Marin M, Gebe N, Akhwale W, Wachsmuth I, et al. A systematic review of health technology assessment tools in sub-Saharan Africa: methodological issues and implications. Health Res policy Syst. 2014;12:66.

65. World Health Assembly. Health intervention and technology assessment in support of universal health coverage, vol. 67; 2014. http://www.who.int/iris/ handle/10665/162870. Accessed 04 June 2018

66. Goldstein B. Cognitive Psychology. Wadsworth, Cengage Learning; 2011. p. 374

\section{Publisher's Note}

Springer Nature remains neutral with regard to jurisdictional claims in published maps and institutional affiliations.

Ready to submit your research? Choose BMC and benefit from:

- fast, convenient online submission

- thorough peer review by experienced researchers in your field

- rapid publication on acceptance

- support for research data, including large and complex data types

- gold Open Access which fosters wider collaboration and increased citations

- maximum visibility for your research: over $100 \mathrm{M}$ website views per year

At BMC, research is always in progress.

Learn more biomedcentral.com/submissions 